\title{
Proximal Urethral Carcinoma
}

National Cancer Institute

\section{Source}

National Cancer Institute. Proximal Urethral Carcinoma. NCI Thesaurus. Code C115334.

A carcinoma that arises from the proximal part of the urethra. 